\title{
Innovative Strategies for Learning and Teaching of Large Differential Equations Classes
}

\author{
Kuppalapalle Vajravelu ${ }^{1^{*}}$ \\ ${ }^{1}$ University of Central Florida, USA \\ * CORRESPONDENCE: $\$ kuppalapalle.vajravelu@ucf.edu
}

\begin{abstract}
Ordinary Differential Equations I, is one of the core courses for science and engineering majors. Practical problem solving in science and engineering programs require proficiency in mathematics. Improving student performance and retention in mathematics classes requires inventive approaches. At the University of Central Florida (UCF) the Department of Mathematics developed an innovative teaching method that incorporated computers, Canvas (Webcourses@UCF), WileyPlus software, and application sessions in large Ordinary Differential Equations I classes. Introduction of new technology, in-class problem solving and application (or discussion) sessions are important factors in the enhancement of students' deep understanding of mathematics. We will detail various components of the course (online homework sets, application sessions and projects, in-class tests, and comprehensive final exam) and discuss how we obtained optimal results enhancing the traditional teaching techniques. Also, how to obtain optimal results without sacrificing the traditional teaching techniques will be brought out. We hope that the details of our experiences and the lessons we learned along the way will be helpful to others who are struggling with the same issues. Also, we provide solutions for quality education and the student-growth. Furthermore, this technique can be used to teach large classes in Science, Technology, Engineering and Mathematics (STEM).
\end{abstract}

Keywords: differential equations, teaching and learning, technology, retention, large class, STEM education

\section{INTRODUCTION}

Differential equations courses have always been a central part of the American baccalaureate degree program in science and engineering. As inter-disciplinary specializations have grown throughout the twentieth century, the ordinary differential equations course has become the course that assures all students, regardless of specialization or intended career, become acquainted with history, science, engineering and mathematics. It is also a major vehicle for cultivating capacities such as communication, critical thinking, quantitative reasoning, and integration of knowledge: It can be summarized as "differential equations are everywhere".

A strong foundation in the knowledge and application of differential equations provides a distinct advantage in the learning of science and engineering concepts. Learning and retaining complex subject matter in science and engineering greatly depends on students' established mathematical proficiency. Effectively teaching differential equations establishes a strong base of knowledge from which all future learning of these concepts is supported. The University of Central Florida has embarked upon an innovative approach for the

\footnotetext{
Article History: Received 1 November $2016 \bullet$ Revised 9 December $2016 \bullet$ Accepted 12 December 2016

(C) 2018 The Author(s). Open Access terms of the Creative Commons Attribution 4.0 International License (http://creativecommons.org/licenses/by/4.0/) apply. The license permits unrestricted use, distribution, and reproduction in any medium, on the condition that users give exact credit to the original author(s) and the source, provide a link to the Creative Commons license, and indicate if they made any changes.
} 
effective teaching of mathematics. Several dynamic techniques have been initiated to deliver a result-centered learning environment.

The development of new digital technologies must have a positive impact in the learning process of mathematics, but the speed that is characteristic of this development limits the time needed to understand the importance of these resources and their inclusion in the courses. On the other hand, a traditional curriculum, the standard in many classrooms, actively resists questioning, and creates difficulties in the establishment of defined criteria that can guide us into making allies with technologies currently available. There are many frameworks (Ismail, Zeynivandnezhad \& Yusof, 2012) available in engaging students in learning mathematics. It is very important to change the teaching techniques, to blend the traditional and modern techniques of learning. Rapid development of technology influenced the teaching techniques. It also affects the teaching and learning of differential equations for undergraduate students.

Kashefi, Ismail, Yusof \& Rahman (2012) analyzed the obstacles undergraduate students face with nonroutine problems. This was due to the weakness of students in understanding the basic concept and the symbols. Also, the students have difficulty in graphical representations. As we all know, there are some problems for students in understanding differential equations. In this paper we present a method of "teaching and learning differential equations". Furthermore, technology change over time caused professors to try many teaching approaches. Most important are techniques that engage the students with the subject and increase their understanding and reasoning. Separating the technology from teaching is a loss for the education field and the students' ability. Dubinsky \&Tall 1991; Kashefi, Ismail, Yusof \& Rahman 2012; and Ismail, Zeynivandnezhad \& Yusof, 2012 proposed several frameworks in integrating computers and technology in their teachings in classrooms. When relating technology to the differential equations learning process, the result undoubtedly steers toward graphing software, be it for computers or calculators. Nevertheless, the integration of these well-known technological resources should not be taken as a guarantee of a better learning process. In our judgment, innovation can only come when the software is implemented correctly and thoughtfully in the curriculum, and when it brings a significant, notable improvement in the teaching and learning process. In this work, we provide some issues to consider when pondering the impact that digital technologies can have when introduced in a visual learning process for differential equations. For this, we have two important factors to consider: the characteristics of the technological environment and the design of didactic activities centered on harnessing these characteristics.

Now-a-days, educators are looking for solutions for quality education and the student-growth. The possible solutions are: (i) Face-to-face teaching versus online teaching, and (ii) Large class versus small class. In this paper we present an "Innovative Teaching of Large Differential Equations Classes" with emphasis on understanding and retaining the subject matter and on the retention rate. We also emphasize applying these skills to day-to-day problems. This teaching method can be modified appropriately and applied to several science and engineering classes. Furthermore, we describe a didactic experience that uses a kind of software created specifically for the improvement of the mathematics learning process. We want to share the design of a sequence of activities carried out in the ordinary differential equations course. It is part of a broad work of educational research that we have been practicing in our institution in order to transform curriculum in mathematics. The custom-made book by Wiley, provides an approach to ordinary differential equations where the desired interaction promotes the development of visualization, modeling, and flexibility between the different mathematical representations. In order to do this, the integration of different specialized mathematical technologies, like graphing software and spreadsheets, has become a key element. It uses technology to favor the interaction a student can have with a problem.

As mentioned earlier, there is a current trend among institutions of higher education to attempt to do more with less without sacrificing the quality of education. As a result, it is not uncommon for sophomore and junior classes to be taught in a large class format. Educators and students are worried about the quality of teaching and high DFW rates which affect time-to-graduation and retention rates. Hence, at UCF, we came up with an innovative teaching program for our large ordinary differential equations classes with an emphasis placed on understanding and retaining the differential equations skills and on the retention rate. Furthermore, an emphasis is placed on applying these skills when addressing real world problems we come across within our personal and professional lives. This teaching method can be modified appropriately and applied to science, engineering, and humanities classes. 


\section{REDESIGNED COURSE STRUCTURE}

In Spring 2015, our department wanted to improve the student learning and retention in the Ordinary Differential Equations I course. To compare the outcomes, we planned to pilot the course in two formats: one in traditional classroom methods (with 49 students) and another redesigned large section (with 112 students), both taught at the same semester. I was asked to coordinate and teach both piloting sections. We were pleased with the outcome which was favorable and positive. Then in Summer 2015, the large class enrollment was increased to 209 students. We continue to teach this course in the new large class format with positive outcome.

In the redesigned Ordinary Differential Equations I course, students spent three hours per week in a large lecture class complemented by one and half hours per week of required small group class meetings facilitated by their GTA mentors.

Part of the planned redesign was a change in the mix of instructional staff teaching the course. The following table provides the mix of instructional personnel teaching the sections pre-project as well as the current mix. Pre-project sections were consistently about 49 students per section. Currently, there are up to 49 students in the traditional sections and up to 200 students in the redesigned sections.

As shown in the table below, we were able to reduce the number of faculty teaching the course. However, we added two Graduate Teaching Assistants (GTAs) per each large section. The GTAs carried out the discussion sessions by solving home work problems and worked out projects related to the day-to-day problems arising in science and engineering.

\begin{tabular}{ccccc}
\hline Semester & \# of sections & \# of faculty & \# of students & \# of students per faculty \\
\hline Fall 2014 & 10 & 10 & 475 & 48 \\
\hline Spring 2015 & 9 & 9 & 489 & $54^{*}$ \\
\hline Fall 2015 & 5 & 5 & 488 & $98^{* *}$ \\
\hline
\end{tabular}

*Due to the addition of one large section

$* *$ Due to the addition of two large sections

\section{NEWLY INTRODUCED COURSE REQUIREMENTS}

Once the decision to redesign our Ordinary Differential Equations I course was made, a change in the course requirements was necessary. The pedagogy of engaging students during class, requiring them to be active learners with their classmates, and the provision of immediate feedback were top priorities of the redesign. The following three components comprised the course requirements:

\section{Online Homework}

Graded online homework and the WileyPlus software packaged with the textbook were introduced into the redesigned course. For these homework assignments to be completed online, students were expected to have access to a computer or they could use a computer in one of the computer labs on the main campus.

Typically, there was an online homework assignment every week. These assignments included about eight to ten questions selected from the textbook. For homework, applied problems were chosen carefully emphasizing the theory. All learning aids were turned off for some problems. When multiple attempts were allowed on a problem, the last submitted answer was used for grading purposes.

\section{Application Sessions and Projects}

During the semester, each student was scheduled to attend one application session each week. While in their application sessions, students worked in small groups to explore and discuss course content and gain experience working as a team while solving ordinary differential equations based application problems. Graduate teaching assistants answered student questions and did several applied problems. These applied problems were intended to help students in completing their projects.

The Instructor and the GTA mentors monitored student progress throughout the semester and intervened with an action plan to help them succeed in the course when it was deemed appropriate. Also, some applied problems arising in science and engineering were assigned as project problems for credit. 


\section{Tests and Final Exam}

There were three (paper and pencil) tests throughout the semester and a comprehensive final exam. These tests and exam were graded using a rubric.

\section{GRADING POLICY}

The following four components were used in grading:

(i) Online Homework: $10 \%$

(ii) Attendance, Quizzes and Projects in Application Sessions: 10\%

(iii) In class tests (3 tests in total): $60 \%$

(iv) Final exam: $20 \%$

The participation component was calculated based on the successful completion of assigned projects, as well as attendance and participation in the discussion classes, and GTA led applications sessions.

The following (typical 10-point) grading scale was used for the course:

\begin{tabular}{cccccc}
\hline Percentage & $\mathbf{9 0} \%-\mathbf{- 1 0 0} \%$ & $\mathbf{8 0} \%-\mathbf{8 9} \%$ & $\mathbf{7 0} \%-\mathbf{7 9} \%$ & $\mathbf{6 0 \%}-\mathbf{6 9 \%}$ & $\mathbf{0 \%}-\mathbf{5 9 \%}$ \\
\hline Letter Grade & $\mathrm{A}$ & $\mathrm{B}$ & $\mathrm{C}$ & $\mathrm{D}$ & $\mathrm{F}$ \\
\hline
\end{tabular}

\section{USE OF TECHNOLOGY}

Technology was used in the large lectures, application sessions, formative and summative assessments, and outside of class assignments. Communication has been shown to have an important role in learning and understanding mathematics (Knuth \& Peressini, 2001). This was a motivating factor in the decision to redesign our differential equations course to provide immediate feedback to students whenever possible. Given the large class size, technology was an essential tool used by faculty and GTAs to provide immediate feedback to students. Canvas was used as a classroom response system.

The instructor used PowerPoint slides and document camera to deliver the material to the live audience. The class notes were posted on the class website. Tegrity (video system) was used to record the live class and video was posted on the class website. Canvas was used as the classroom response system. PowerPoint slides provided basic content for the course but given concerns of attention span, we felt that built in breaks during the lecture were necessary. A change in presentation format from PowerPoint slides to the document camera provided the most subtle type of break.

Researching ways of improving conceptual learning in the sciences, the Galileo Project Group at Harvard found that breaking up lecture inputs with concept questions and in-class discussions was beneficial (Crouch \& Mazur, 2001).

Students completed weekly online homework assignments which were designed to provide them with practice problems. Using technology to complete homework assignments online provided immediate feedback to the students on their submitted answers. The online homework system was also used to facilitate skills tests which assessed students on skill/drill learning objectives.

Application sessions led by graduate teaching assistants (GTAs) made use of technology as well. The GTAs monitored students' progress and gave students weekly feedback regarding their progress.

\section{ASSESSMENT OF RESULTS}

\section{Success Rates}

Includes all students enrolled after add/drop who earned a C or higher: During Spring 2015, it was 57\% with redesigned teaching compared to $55 \%$ with traditional teaching.

\section{Student Survey Responses}

It is not unusual for students, particularly sophomores and juniors, enrolled in large lecture classes to state that they "do not know anyone in the class". Our redesigned course structure provided the opportunity for 
students to be active learners with their classmates. Students were often working together during their application sessions to solve a problem. It is the belief of the author that the increase in engagement with their classmates resulted in a better sense of belonging as evidenced by survey responses.

When the class size increases, the amount of personal interaction the teaching team has with the students often decreases. Engaging with the students and providing feedback resulted in survey responses indicating that $55 \%$ of the students had met with their application session leader or had been contacted by them, and $82 \%$ responded that their application session leader had spoken with them personally about an exercise problem.

\section{CONCLUSIONS}

We have redesigned the course to have a more consistent student experience in terms of content and assessment. When comparing the traditional teaching methodology with the redesigned course, we found almost the same passing rate for the redesigned class. Also, this model allows students to watch the video and class notes related to the course at their convenience. This model helps working students and the crowded University Campuses. However, they need to attend one hour applications secessions. We tried this teaching model with two hundred plus students. It can be tried with any number of students. The author initiated this model in Spring 2015 and continued its use in Summer 2015. Even now this model is being used at the author's institution. Also, when comparing the traditional teaching methodology with the redesigned course, we found a substantial increase in the average number of students per faculty in the redesigned sections. That is, during the past few semesters the average number of students per faculty was around 98 with redesigned teaching compared to 48 with traditional teaching.

\section{Disclosure statement}

No potential conflict of interest was reported by the authors.

\section{Notes on contributors}

Kuppalapalle Vajravelu - University of Central Florida, USA.

\section{REFERENCES}

Crouch, C. H., \& Mazur, E. (2001). Peer Instruction: Ten years of experience and results. American Journal of Physics, 69, 970-977. https://doi.org/10.1119/1.1374249

Dubinsky, E., \& Tall, D. (1991). Advanced Mathematical Thinking and the Computer, Tall D.O. (ed.), Advanced Mathematical Thinking, Kluwer: Holland, 231-248.

Ismail, Z., Zeynivandnezhad, F., \& Yusof, Y. M. (2012). Mathematical Thinking in Differential Equations through Computer Algebra system: a theoretical framework. Procedia-social and behavioral science, $56,537-545$.

Kashefi, H., Ismail, Z., Yusof, Y. M., \& Rahman, R. A. (2012). Fostering mathematical thinking in the learning of multivariable calculus through computer-based tools. Procedia, Social and Behavioral Sciences, 8, 5534-5540. https://doi.org/10.1016/j.sbspro.2012.06.471

Knuth, E., \& Peressini, D. (2001). Unpacking the nature of discourse in mathematics classrooms. The National Council of Teaching Mathematics, 6(5), 320-325. 